\title{
Cross-Sectional Study of Varicella Zoster Virus Immunity in Healthy Korean Children Assessed by Glycoprotein Enzyme-Linked Immunosorbent Assay and Fluorescent Antibody to Membrane Antigen Test
}

\author{
Yunhwa Kim ${ }^{1}$, Ji-Young Hwang ${ }^{1}$, Kyung-Min Lee ${ }^{1}$, Eunsil Lee ${ }^{2}$ and Hosun Park ${ }^{1,3, *(\mathbb{D})}$ \\ 1 Department of Microbiology, College of Medicine, Yeungnam University, Daegu 42415, Korea; \\ linbi@ynu.ac.kr (Y.K.); generous81@naver.com (J.-Y.H.); blackxg@naver.com (K.-M.L.) \\ 2 Department of Pediatrics, College of Medicine, Yeungnam University, Daegu 42415, Korea; les2055@ynu.ac.kr \\ 3 Immunogenicity Evaluation Laboratory, Clinical Trial Center, Yeungnam University Medical Center, \\ Daegu 42415, Korea \\ * Correspondence: hspark@ynu.ac.kr; Tel.: +82-53-640-6943
}

check for updates

Citation: Kim, Y.; Hwang, J.-Y.; Lee,

K.-M.; Lee, E.; Park, H.

Cross-Sectional Study of Varicella Zoster Virus Immunity in Healthy Korean Children Assessed by Glycoprotein Enzyme-Linked Immunosorbent Assay and Fluorescent Antibody to Membrane Antigen Test. Vaccines 2021, 9, 492. https://doi.org/10.3390/ vaccines 9050492

Academic Editors: Artur Summerield and Magdalena A. Berkowska

Received: 13 April 2021

Accepted: 7 May 2021

Published: 12 May 2021

Publisher's Note: MDPI stays neutral with regard to jurisdictional claims in published maps and institutional affiliations.

Copyright: (c) 2021 by the authors. Licensee MDPI, Basel, Switzerland. This article is an open access article distributed under the terms and conditions of the Creative Commons Attribution (CC BY) license (https:// creativecommons.org/licenses/by/ $4.0 /)$.
Abstract: The prevalence of varicella is especially high among children in the age group of 4-6 years in South Korea, regardless of vaccination. We investigated the immune status of healthy children enrolled in day-care centers and compared pre- and post-vaccination immunity. Antibody titers were measured using a glycoprotein enzyme-linked immunosorbent assay (gpEIA) kit, and the seroconversion rate was assessed using a fluorescent antibody to membrane antigen (FAMA) test. Among 541 vaccinated children, 109 (20.1\%) had breakthrough varicella. However, 13 (72.2\%) of the 18 unvaccinated children had a history of varicella. The gpEIA geometric mean titers (GMTs) of pre- and 5 weeks post-vaccination in 1-year-old children were 14.7 and $72 \mathrm{mIU} / \mathrm{mL}$, respectively, and the FAMA seroconversion rate was 91.1\%. The gpEIA GMTs of 2-, 3-, 4-, 5-, and 6-year-old children were 104.1, 133.8, 223.5, 364.1, and $353.0 \mathrm{mIU} / \mathrm{mL}$, respectively. Even though the gpEIA GMT increased with age, the pattern of gpEIA titer distribution in 4- to 6-year-old vaccinees without varicella history represented both waning immunity and natural boosting immunity. These results suggest that some vaccinees are vulnerable to varicella infection. Therefore, it is necessary to consider a two-dose varicella vaccine regimen in South Korea.

Keywords: varicella; vaccine; immunity; glycoprotein; ELISA; FAMA

\section{Introduction}

Varicella zoster virus (VZV) causes varicella (chickenpox), which is a highly contagious disease in children with primary infection. The virus persists in individuals during their lifetime and may subsequently reactivate and cause herpes zoster, especially in senescent or immunocompromised individuals [1]. Major symptoms of varicella are fever and rash; however, it sometimes leads to severe complications such as encephalitis, varicella pneumonia, or death [2,3].

A live-attenuated vaccine for varicella has been selectively used in Korea since 1988, and it has been included in the National Immunization Program (NIP) in Korea since 2005 for children aged 12-15 months with a single dose schedule [4]. In Korea, several domestic and imported vaccines have been used, and some vaccines have been discontinued. The varicella vaccine coverage rates for children aged 6 years or less in Korea were 88.3\%, 96.8\%, and $99.0 \%$ in 2007, 2008, and 2009, respectively, and they were over 97\% between 2016 and 2019 [5-8]. Nevertheless, varicella outbreaks occasionally occur in day-care centers or primary schools, even among vaccinated children with mild clinical presentation [9]. Until now, only a small number of reports have been published regarding the long-term 
immunogenicity of Korean children after varicella vaccination [10]. Therefore, it is necessary to evaluate the immune status of the most vulnerable age groups to investigate the basis of varicella outbreaks.

Currently, an enzyme-linked immunoassay kit using a VZV glycoprotein (gpEIA) (Birmingham, UK), which is calibrated to international units (IUs), is available. Therefore, we investigated gpEIA antibody titers in children and compared the seroconversion rate as evaluated by fluorescent antibody to membrane antigen (FAMA) testing.

\section{Materials and Methods}

\subsection{Subjects}

In a cross-sectional study, 572 children aged 2 to 6 years old were enrolled, and blood samples were collected during annual health examinations at 13 day-care centers in Gyeongsan city from April 2009 to June 2009. For the vaccination study, 45 children aged 1 year old were enrolled in Yeungnam University Hospital (Daegu, Korea) between May 2013 and August 2015, and blood was collected before and $5 \pm 1$ weeks after varicella vaccination (Suduvax ${ }^{\circledR}$, GreenCross Company, Yongin-si, Korea). Approximately 2-3 mL of blood was collected, and all sera were stored at $-70^{\circ} \mathrm{C}$ until use. These studies complied with the Institutional Review Board of Yeungnam University Medical Centers (PCR-09-23, YUH-2013-01-330), and written informed consent was obtained from all of the enrolled children's parents. Thirteen blood samples were excluded, and 604 samples were analyzed in this study.

\subsection{Glycoprotein Enzyme-Linked Immunoassay (gpEIA)}

Antibody titers of all samples were measured using a VaccZyme ${ }^{\mathrm{TM}}$ VZV glycoprotein IgG Low EIA kit (detection range 10-810 mIU/mL, Binding site, Birmingham, United Kingdom, UK). Samples beyond the detection limit of the Low kit were re-analyzed using the Screening kit (detection range $0.5-10 \mathrm{IU} / \mathrm{mL}$ ). These procedures were performed according to the manufacturer's instructions.

\subsection{Fluorescent Antibody to Membrane Antigen (FAMA) Test}

FAMA tests were performed using 2-fold serially diluted sera as previously described [11,12]. Phosphate-buffered saline-diluted WHO international standard for VZV immunoglobulin (NIBSC W1044, UK) to $7.8 \mathrm{mIU} / \mathrm{mL}$ was used as a positive cut-off reference serum. Cells presenting archetypal membrane fluorescence were regarded as positive using an Axioscope fluorescence microscope equipped with an HBO 50 mercury lamp (Carl Zeiss, Oberkochen, Germany). FAMA titers $>$ 1:16 were considered to be positive.

\subsection{Statistical Analysis}

$\mathrm{X}^{2}$ tests were used to examine statistical differences between age groups, and paired $t$-tests were used for the differences before and after vaccination with varicella. Ageassociated increases in geometric mean titer (GMT) changes were assessed by one-way ANOVA (SPSS V. 25.0, IBM SPSS, Inc., Chicago, IL, USA). The Kruskal-Wallis test using Tukey's multiple comparisons test were used to determine the waning of GMT depending on the duration of the onset of varicella. All tests were performed at a two-sided significance level of $p<0.05$ (SPSS V. 25.0, IBM SPSS, Inc., Chicago, IL, USA, GraphPad Prism V. 9.0.1., GraphPad Software Inc., San Diego, CA, USA).

\section{Results}

\subsection{Characteristics of Enrolled Children}

For the cross-sectional study of healthy children, a total of 572 children aged 2-6 years were enrolled in this investigation; however, 559 children were included in the final data analysis because of insufficient information regarding 13 children. In all, 66, 133, 158, 149, and 53 children aged 2, 3, 4, 5, and 6 years, respectively, were included (Table 1). Based on a parent questionnaire, 541 children $(96.8 \%)$ had been vaccinated, and $18(3.2 \%)$ were 
not vaccinated. Vaccinations involved four different vaccines; SuduVax (62.2\%), Varilrix (10.7\%) (GSK, Brentford, UK), Vari-L (1.1\%) (Changchun Institute of Biological Products, Changchun-si, China), CJ Sudu vaccine (0.2\%) (Cheil Jedang, Seoul, South Korea), and unknown vaccines accounted for $25.7 \%$ of the cases. Among the vaccinees, 432 (79.9\%) had no history of varicella, and 109 (20.1\%) had breakthrough varicella disease. The percentage of children with varicella history among vaccinees were significantly increased from 9.1, $8.5,20.3,33.1$, to $28.0 \%$ in age $2,3,4,5$, and 6 years old, respectively (Table 1$)\left(\mathrm{X}^{2}\right.$ test for trend, $p<0.0001)$. Among children who had not been vaccinated, $5(27.8 \%)$ had no history of varicella, and $13(72.2 \%)$ had experienced varicella infection (Table 1$)$. For the vaccine study, 45 one-year-old children with no history of varicella were enrolled. Therefore, in all, 604 children were included in the analysis. Among them, 312 (51.7\%) were male and 292 $(48.3 \%)$ were female (Table 2$)$.

Table 1. Characteristics of children enrolled in the cross-sectional study.

\begin{tabular}{ccccc}
\hline & \multicolumn{2}{c}{$\begin{array}{c}\text { Vaccinated } \\
(\boldsymbol{n}=\mathbf{5 4 1 )}\end{array}$} & \multicolumn{2}{c}{$\begin{array}{c}\text { Unvaccinated } \\
(\boldsymbol{n}=\mathbf{1 8})\end{array}$} \\
\cline { 2 - 5 } Age (yr) & \multicolumn{2}{c}{ Varicella Hx } & \multicolumn{2}{c}{ Varicella Hx } \\
\cline { 2 - 5 } & - & + & 0 & + \\
\hline 2 & 60 & 6 & 0 & 0 \\
3 & 119 & 11 & 0 & 5 \\
4 & 122 & 31 & 3 & 4 \\
5 & 95 & 47 & 2 & 1 \\
6 & 36 & 14 & $5(27.8)$ & $13(72.2)$ \\
\hline Subtotal (\%) & $432(79.9)$ & $109(20.1)$ & &
\end{tabular}

Table 2. Gender distribution of children enrolled in the cross-sectional and vaccine studies.

\begin{tabular}{ccc}
\hline \multirow{2}{*}{ Age $(\mathbf{y r})$} & \multicolumn{2}{c}{ Total $(\boldsymbol{n = 6 0 4 )}$} \\
\cline { 2 - 3 } & Male & Female \\
\hline 1 & 20 & 25 \\
2 & 29 & 37 \\
3 & 66 & 67 \\
4 & 81 & 77 \\
5 & 92 & 57 \\
6 & 24 & 29 \\
\hline Subtotal $(\%)$ & $312(51.7)$ & $292(48.3)$ \\
\hline
\end{tabular}

\section{2. gpEIA Titer and FAMA Seroprevalence of Pre- and Post-Vaccination Sera}

The gpEIA GMT of 1-year-old children $(n=45)$ was 14.7 and $72 \mathrm{mIU} / \mathrm{mL}$ before and after vaccination, respectively (Table 3) and the gpEIA GMT of post-vaccination was significantly different with pre-vaccination (paired t-test, $p<0.0001$ ). The range of gpEIA titers was 4.4-53.4 and 10.7-359.1 $\mathrm{mIU} / \mathrm{mL}$ before and after vaccination, respectively (Table 3, Figure 1a). In pre-vaccination sera, gpEIA titers in 14 sera (31.1\%) were lower than $10 \mathrm{mIU} / \mathrm{mL}$, in 17 sera (37.8\%) were between 10 and $<20 \mathrm{mIU} / \mathrm{mL}$, in 9 sera $(20 \%)$ were between 20 and $<30 \mathrm{mIU} / \mathrm{mL}$, in 2 sera $(4.4 \%)$ were between 30 and $<40 \mathrm{mIU} / \mathrm{mL}$, in 2 sera $(4.4 \%)$ were between 40 and $<50 \mathrm{mIU} / \mathrm{mL}$, and in one serum sample $(2.2 \%)$, the titer was $53.4 \mathrm{mIU} / \mathrm{mL}$ (Figure 1a). In contrast, only 3 sera $(6.7 \%)$ showed titers lower than $30 \mathrm{mIU} / \mathrm{mL}$, 6 sera (13.3\%) showed between 30 and $<40 \mathrm{mIU} / \mathrm{mL}, 5$ sera $(11.1 \%)$ showed between 40 and $<50 \mathrm{mIU} / \mathrm{mL}$, 17 sera (37.8\%) showed between 50 and $<100 \mathrm{mIU} / \mathrm{mL}$, and 14 sera (31.1\%) showed titers between 100 and $400 \mathrm{mIU} / \mathrm{mL}$ after vaccination (Figure 1a). Therefore, the antibody titer of $88.9 \%$ of pre-vaccinated sera was $<30 \mathrm{mIU} / \mathrm{mL}$, while $93.3 \%$ of post-vaccinated sera showed titers $>30 \mathrm{mIU} / \mathrm{mL}$. The percentage of children whose 
antibody titers were $>50 \mathrm{mIU} / \mathrm{mL}$ was $2.2 \%$ and $68.9 \%$ in the pre- and post-vaccination groups, respectively.

Table 3. gPEIA and FAMA results of vaccine study paired sera in 1-year-old children.

\begin{tabular}{ccc}
\hline Measurements & $\begin{array}{c}\text { Pre-Vaccination } \\
(\boldsymbol{n}=\mathbf{4 5})\end{array}$ & $\begin{array}{c}\text { Post-Vaccination } \\
(\boldsymbol{n}=\mathbf{4 5})\end{array}$ \\
\hline gpEIA GMT $(\mathrm{mIU} / \mathrm{mL})$ & 14.7 & $72.0^{* * * *}$ \\
gpEIA titer range $(\mathrm{mIU} / \mathrm{mL})$ & $4.4-53.4$ & $10.7-359.1$ \\
FAMA positive rate $(\%)$ & 0 & 91.1 \\
FAMA GMT & 1.3 & $41.6^{* * * *}$ \\
\hline
\end{tabular}

**** $p$ value $<0.0001$.

(a)

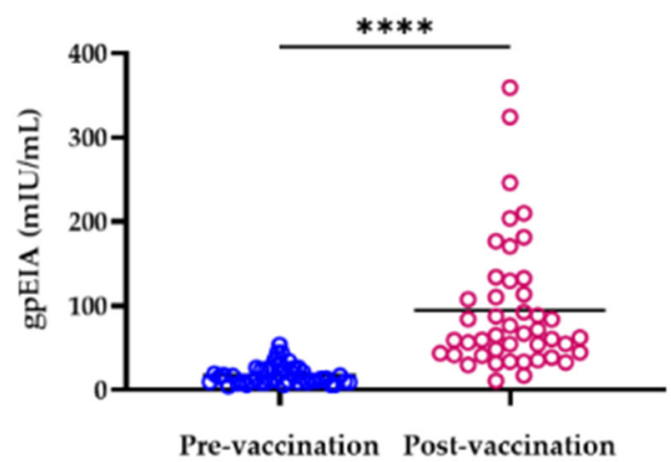

(b)

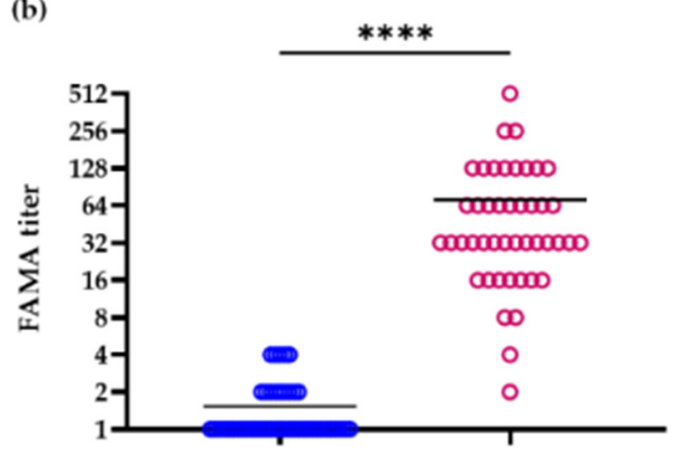

Pre-vaccination Post-vaccination

Figure 1. Distribution of gpEIA antibody titers (a) and FAMA titers (b) in pre- and post-vaccination paired sera. $* * * * p$ value $<0.0001$, bar represents mean.

All 45 pre-vaccination sera were negative in FAMA testing. The seroconversion rate of post-vaccination sera was $91.1 \%$ and the FAMA GMT of post-vaccination was significantly different with pre-vaccination (paired $t$-test, $p<0.0001$ ) (Table 3). FAMA GMT titers were 1.3 and 41.6 in pre- and post-vaccination sera, respectively (Table 3). The range of FAMA titers was $<2-4$ and $2-512$ in pre- and post-vaccination sera, respectively (Figure $1 b$ ). Four $(8.9 \%)$ post-vaccination sera presented negative FAMA results. Among these, the gpEIA titers of three post-vaccination sera were $<30 \mathrm{mIU} / \mathrm{mL}$ (Table 4). However, the gpEIA titers of subject No. 37, who did not present seroconversion in FAMA test results, were approximately $50 \mathrm{mIU} / \mathrm{mL}$ both in pre- and post-vaccination sera, and gpEIA titers were not particularly different after vaccination (Table 4).

Table 4. Comparison of FAMA and gpEIA titers in subjects who had not seroconverted after vaccination.

\begin{tabular}{ccccc}
\hline \multirow{2}{*}{ Subject No. } & \multicolumn{2}{c}{ FAMA } & \multicolumn{2}{c}{ gpEIA (mIU/mL) } \\
\cline { 2 - 5 } & Pre-Vaccination & Post-Vaccination & Pre-Vaccination & Post-Vaccination \\
\hline 28 & $<2$ & 4 & 6.42 & 16.96 \\
34 & $<2$ & 2 & 8.70 & 10.65 \\
37 & 4 & 8 & 53.43 & 59.53 \\
42 & 2 & 8 & 9.53 & 29.62 \\
\hline
\end{tabular}

\section{3. gpEIA GMT of 2- to 6-Year-Old Children}

The gpEIA GMT of 2- to 6-year-old children was $215.1 \mathrm{mIU} / \mathrm{mL}$. The gpEIA GMTs of vaccinees who had developed breakthrough varicella $(1423.4 \mathrm{mIU} / \mathrm{mL})$ were 10.8 -fold higher than those of vaccinees without varicella history $(131.4 \mathrm{mIU} / \mathrm{mL})$ (Table 5). In vaccinated children, gpEIA GMTs significantly increased with age regardless of varicella 
history $(p<0.05)$. Meanwhile, the gpEIA GMTs of children who had neither been vaccinated nor had varicella history were $<10 \mathrm{mIU} / \mathrm{mL}$.

Table 5. gpEIA GMT based on vaccination and varicella histories in 2- to 6-year-old children.

\begin{tabular}{|c|c|c|c|c|c|}
\hline \multirow{3}{*}{$\begin{array}{l}\text { Age } \\
(y r)\end{array}$} & \multirow{3}{*}{$\begin{array}{c}\text { Total } \\
(\mathrm{mIU} / \mathrm{mL}) *\end{array}$} & \multirow{2}{*}{\multicolumn{2}{|c|}{$\begin{array}{c}\begin{array}{l}\text { Vaccinated } \\
(\mathrm{mIU} / \mathrm{mL})\end{array} \\
\text { Varicella }\end{array}$}} & \multirow{2}{*}{\multicolumn{2}{|c|}{$\begin{array}{c}\begin{array}{c}\text { Unvaccinated } \\
(\mathrm{mIU} / \mathrm{mL})\end{array} \\
\text { Varicella }\end{array}$}} \\
\hline & & & & & \\
\hline & & - & + & - & + \\
\hline 2 & 104.1 & 85.3 & 762.7 & NA & NA \\
\hline 3 & 133.8 & 114.0 & 571.5 & NA & 378.2 \\
\hline 4 & 223.5 & 133.0 & 1439.3 & NA & 682.2 \\
\hline 5 & 365.1 & 167.1 & 1692.9 & 9.4 & 1987.2 \\
\hline 6 & 352.9 & 220.4 & 2076.2 & 7.2 & 330.0 \\
\hline Total & 215.1 & 131.4 & 1423.4 & 8.4 & 782.3 \\
\hline
\end{tabular}

NA; there were no applicable study subjects, ${ }^{*} p$ value $<0.05$.

\subsection{Distribution of gpEIA Antibody Titer among Vaccinees without Varicella History}

The range of the gpEIA antibody titer of 477 vaccinees without varicella history was very broad, ranging from 1.3 to $51,080 \mathrm{mIU} / \mathrm{mL}$. The distribution of antibody titers showed that the majority of children had titers between 1.3 and $2.4 \log _{10} \mathrm{mIU} / \mathrm{mL}$ (20.2-310.9 mIU / mL) in all age groups, including 5 weeks after vaccination (Figure 2 ). The distribution of antibody titers was broadened in $>3$-year-old children with increasing titers. However, peak incidences were left shifted to $1.3-1.6 \log _{10} \mathrm{mIU} / \mathrm{mL}(20.6-50.0 \mathrm{mIU} / \mathrm{mL})$ in 5- and 6-year-old children compared to 1.7-2.0 $\log _{10} \mathrm{mIU} / \mathrm{mL}(51.1-120.4 \mathrm{mIU} / \mathrm{mL})$ at 1 year post-vaccination and 2-4-year-old groups (Figure 2).

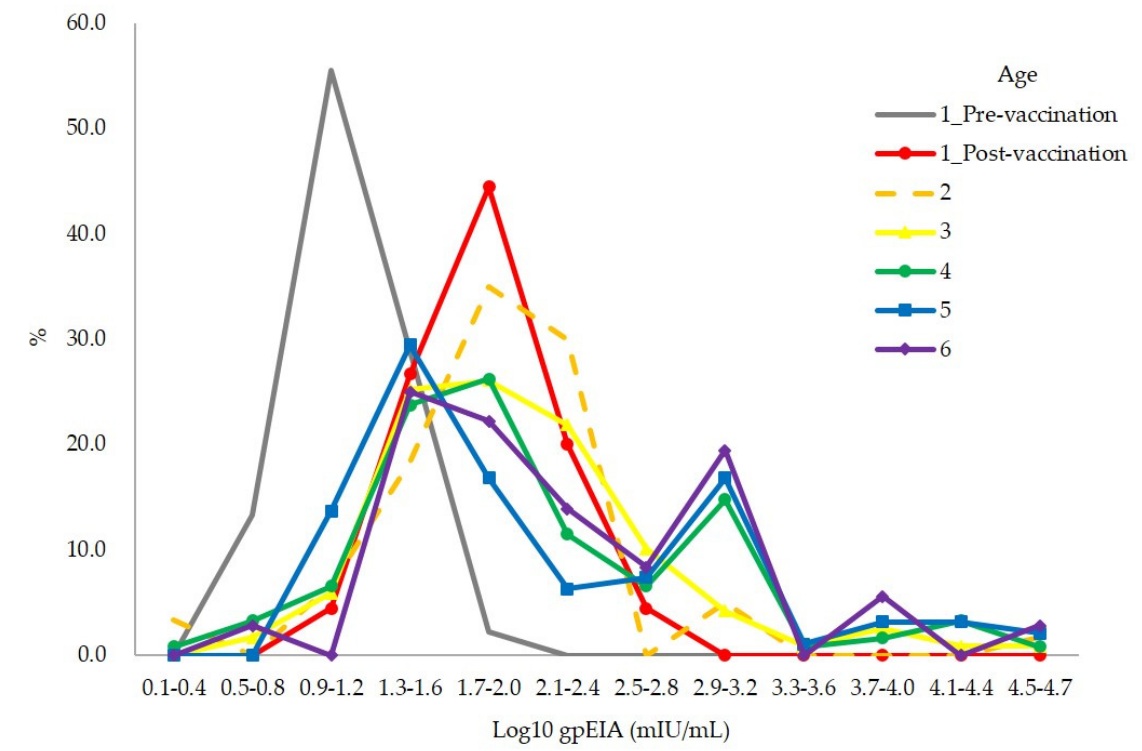

Figure 2. Distribution of gpEIA antibody titers in 477 children who were vaccinated without varicella history.

\subsection{Waning of Immunity among Vaccinees with Varicella History}

To evaluate the waning of immunity, gpEIA GMT of 109 vaccinees with varicella history was analyzed by the duration between blood collection and the onset of varicella disease. gpEIA GMTs were $3.55 \log _{10} \mathrm{mIU} / \mathrm{mL}$ within 6 months of the onset of varicella, $2.95 \log _{10} \mathrm{mIU} / \mathrm{mL}$ between 6 and 18 months, $2.71 \log _{10} \mathrm{mIU} / \mathrm{mL}$ between 18 and 30 months, and $2.40 \log _{10} \mathrm{mIU} / \mathrm{mL}$ after 30 months. The significant decreasing tendency 
in GMT values was evident as time passed until 30 months after the onset of varicella (Kruskal-Wallis test, $p<0.01$ ) (Figure 3).

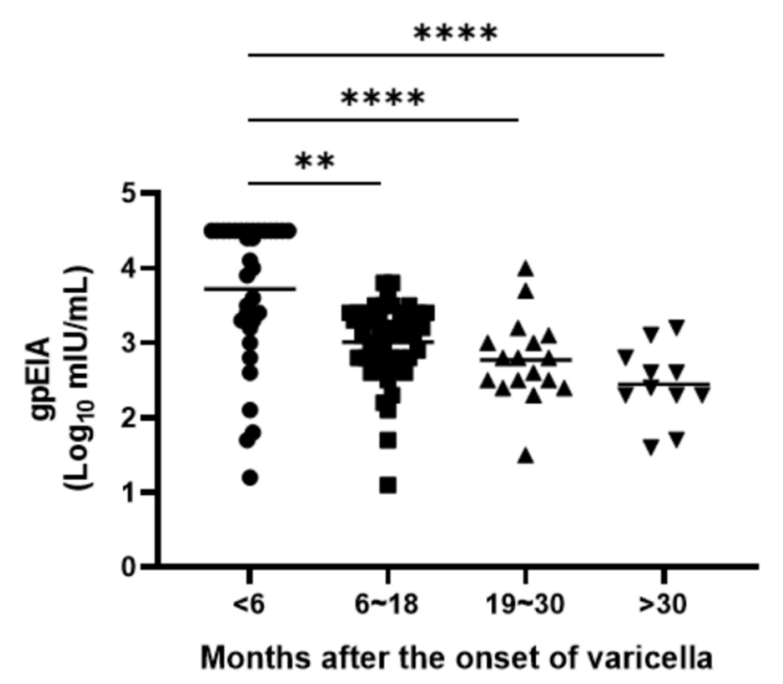

Figure 3. gpEIA titers of 109 vaccinees with varicella history according to the time elapsed from varicella disease. The $p$ values were calculated using Kruskal-Wallis test using Tukey's multiple comparisons test. ${ }^{* *} p<0.01,{ }^{* * * *} p<0.0001$.

\section{Discussion}

In this study, 2- to 6-year-old healthy Korean children were enrolled to evaluate their varicella immune status. Since the varicella vaccine has been included in the NIP since 2005, only $3.2 \%$ of the enrolled children were unvaccinated. The vaccine coverage rate $(96.8 \%)$ was comparable to the previous studies after 2008 in Korea [5,7]. This rate was about 20\% higher than 2001 survey data, which was performed before varicella vaccine was included in NIP [4]. Four hundred two children (74.3\%) among total 541 vaccinees were inoculated with two domestic and two imported vaccines, SuduVax (GreenCross Company, Yongin-si, Korea), CJ Suduvaccine (Cheil Jedang, Seoul, Korea), Varilrix (GSK, Brentford, UK), or VariL (Changchun Institute of Biological Products, Changchun-si, China). However, vaccine brands were not confirmed in 139 (25.7\%) vaccinees. During 2004 to 2008, three other domestic varicella vaccines such as Boryung Sudu vaccine (Boryung Biopharma, Seoul, Korea), Varicella-Kovax (KOREAVACCINE, Ansan-si, Korea), and Varimmune (DongShin Pharmatheutical, Seoul, Korea) were also used in Korea. SuduVax was made with MAV06 strain, and other vaccines were made with strains originated from vOka strain. SuduVax is most prevalent varicella vaccine in Korea. Contrastingly, CJ Sudu vaccine, Boryung Sudu vaccine, Varicella-Kovax, and Varimmune had been withdrawn. There is not enough efficacy data for all of the varicella vaccines used in Korea, especially in healthy children. In this study, all children who had been neither vaccinated nor had prior varicella history were seronegative and naïve to varicella, except for one child (data not shown). VZV is a highly contagious infectious agent with a basic reproductive number R0 of 10-12; therefore, the prevalence of varicella was significantly higher in unvaccinated children $(72.2 \%)$ than in vaccinated children $(20.1 \%)$ (chi-square test, $p<0.05)$. The varicella attack rates in unvaccinated children are $78-82 \%, 72.5 \%, 48 \%, 72.3-80 \%$, and $64.5 \%$ in the United States (USA), Spain, Germany, Southern Italy, and Turkey, respectively [13-18]. Accordingly, the prevalence of varicella in unvaccinated children in this study (72.2\%) was comparable to that in other countries except Germany. Furthermore, the breakthrough rate of varicella in communities with single one-dose vaccination schedules was reported to be $23 \%, 22.9 \%, 19 \%, 12.7-32.1 \%$, and $27.7 \%$ in the US, Spain, Germany, Southern Italy, and Turkey, respectively [13,15-19]. Therefore, the breakthrough rate in this study $(20.1 \%)$ was not particularly different from those reported in other countries. There was no difference in the incidence of varicella according to gender ( $p>0.05$, data not shown). 
In this study, all of 45 pre-vaccination sera were FAMA negative, and the FAMA seroconversion rate was $91.1 \%$ at 5 weeks after vaccination. Vaccine failure was found in four children (8.9\%). In the US, the FAMA seroconversion rate is approximately $80 \%$ after one dose of vaccine, and many outbreaks of varicella have been reported [20,21], with previous Korean data for the same being reported as 76.7\% [22]. Therefore, the FAMA seroconversion rate in our study was slightly higher than that reported in other studies. VZV is a very labile virus, and it is sensitive to temperature, so the transportation and storage of vaccine should be well-controlled. Cold chain management policy was not mandatory in Korea until the early 2000s. Therefore, there was a possibility of reduced vaccine potency before vaccination, and it would be one of the reasons of vaccine failure. To quantify the amount of antibody in children, gpEIA antibody titers were measured. The gpEIA GMT of pre-vaccination sera was $14.7 \mathrm{mIU} / \mathrm{mL}$ (negative level) and gpEIA GMT was increased 4.9 -fold $(72.0 \mathrm{mIU} / \mathrm{mL}) 5$ weeks after vaccination in 1-year-old children. One Korean varicella seroepidemiological study evaluated using Enzygnost VZV IgG ELISA kits (Siemens Healthcare Diagnostics, Eschborn, Germany) showed that the seroprevalence of 1-year-old children is approximately $80 \%$ when the equivocal range of ELISA is included as being considered positive [23]. According to a report from the European seroepidemiology network 2, the interpretation criteria of the Enzygnost VZV IgG ELISA diagnostic kit were as follows: positive $(>100 \mathrm{mIU} / \mathrm{mL})$, equivocal $(50-100 \mathrm{mIU} / \mathrm{mL})$, or negative $(<50 \mathrm{mIU} / \mathrm{mL})$. The VaccZyme ${ }^{\mathrm{TM}}$ gpEIA kit is different from the Enzygnost ELISA kit because it uses glycoproteins and not whole VZV antigens for coating antigens. Therefore, it is difficult to compare the two kits. If $50 \mathrm{mIU} / \mathrm{mL}$ was applied as the cut-off value for the gpEIA kit, the seroconversion rate as measured by gpEIA was $68.9 \%$, and the sensitivity and specificity were $73.1 \%$ and $95.9 \%$, respectively. However, if $30 \mathrm{mIU} / \mathrm{mL}$ is applied as the cut-off value, the seroconversion rate was $93.3 \%$, and the sensitivity and specificity were $100 \%$ and $95.9 \%$, respectively. Since the FAMA seroconversion rate here was $91.1 \%$, the acceptable gpEIA cut-off value for the varicella vaccine might be between 30 and $50 \mathrm{mIU} / \mathrm{mL}$. Therefore, more large-scale vaccine follow-up studies are necessary to obtain a precise cut-off value for gpEIA kits.

The gpEIA GMT of 2- to 6-year-old vaccinated children without prior varicella history was $215.1 \mathrm{mIU} / \mathrm{mL}$, and the gpEIA GMTs of each age group were gradually increased with age from 104.1 to $352.9 \mathrm{mIU} / \mathrm{mL}$ (Table 5). This is considered to be an asymptomatic natural boosting effect. In fact, there were outbreaks in two out of the 13 day-care centers studied, just a few months before blood collection. However, $138(63.3 \%)$ of the 218 vaccinated children in the two day-care centers did not have a history of varicella. The gpEIA GMT of the 138 children $(220.8 \mathrm{mIU} / \mathrm{mL}$ ) was approximately 2-fold higher than that of the vaccinees without varicella history in 11 other day-care centers $(103.0 \mathrm{mIU} / \mathrm{mL})$. Post-vaccination gpEIA titers showed only one narrow peak between 1.7 and $2.0 \log _{10} \mathrm{mIU} / \mathrm{mL}$ (Figure 2, Age 1_Post). However, above 2 years of age, the range of gpEIA antibody titers widened, and a second peak also appeared, and the peak incidence was left-shifted to $1.3-1.6 \log _{10}$ $\mathrm{mIU} / \mathrm{mL}$ at 5 to 6 years of age (Figure 2). According to previous data using Enzygnost anti-VZV/IgG ELISA kit, seropositive rates were gradually decreased from 1 year (65\%) to 4 years $(49 \%)$ old and then increased after 5 years old $[4,24]$. So, our data and previous data suggested that some children displayed waning vaccine-induced immunity, while others exhibited an asymptomatic natural boosting effect.

Vaccinees with varicella history had 10.8-fold higher gpEIA titer (GMT: $1423.4 \mathrm{mIU} / \mathrm{mL}$ ) than children who had been vaccinated without varicella history (GMT: $131.4 \mathrm{mIU} / \mathrm{mL}$ ), and this result is also similar to that from a previous study [25]. According to single nucleotide polymorphism analysis, there are 24 vaccine-specific sites in attenuated VZV genomes compared to wild-type VZV, most of them consist of the substitution of an AT to GC pair [26]. Even though it is unclear which vaccine sites are related with virulence or antigenicity, both virulence and antigenicity might be attenuated in vaccine strains. We found an interesting phenomenon in which antibody titers waned rapidly in naturally infected children. The gpEIA GMT was approximately 10-fold lower after 30 months than 
within 6 months after the onset of varicella (Figure 3). However, this study design was cross-sectional and not a follow-up study; we could not confirm the changes in antibody titer in each individual child.

In the US, a two-dose regimen was recommended by the Centers for Disease Control and Prevention to control breakthrough varicella infections [27]. Varicella vaccine has been used as a routine vaccination in many other countries such as Germany, Australia, Canada, Italy, Spain, Israel, Brazil, and Japan. Among them, Germany, Australia, Italy, Spain, and Japan have implemented NIP protocol of two-dose varicella vaccination [28-32]. However, a single dose regimen has been employed in Korea. It is reported that even though the incidence of varicella in post-vaccination birth cohorts is lower than that in pre-vaccination birth cohorts, varicella prevalence is nevertheless high in 4 to 6-year-old children [33]. Our data also showed that varicella incidences of vaccinees were much higher in 4 (20.3\%), 5 $(33.1 \%)$, and $6(28 \%)$-year-old children compared to $2(9.1 \%)$ and $3(8.5 \%)$-year-old children. Therefore, we followed up the incidence of breakthrough varicella in participants by phone survey based on parental responses 7 years later. Only 75 of the 559 children responded to the survey. Of the 75 children, 20 (26.7\%) experienced varicella when they were of primary school age. There is one prospective case-control and one retrospective case-control studies to examine varicella vaccine effectiveness in Korea; both studies showed that a one-dose regimen is not enough to protect breakthrough infection, especially after 4 years old [22,34]. According to a case-control study conducted with children over 4 years old in the USA, the vaccine effectiveness of one dose and two doses was $86.0 \%$ and $98.3 \%$, respectively [35]. In Hong Kong, the effectiveness of a one-dose vaccine was $69.4 \%$. It increased to $93.4 \%$ when the primary dose was given at 12 months and then a second dose was given at around 6 years old [36]. However, they mentioned that the two-dose regimen with a short interval should be considered to reduce varicella outbreaks. Considering all of the above results, it appears to be reasonable to boost immunity by inoculation before 4 years of age.

This study had certain limitations. First, we enrolled children in only two cities, so the results of this study may not be representative of all South Korean children. Nonetheless, the vaccine coverage rate was comparable with that of other studies [6]. Second, because this was a cross-sectional study, we could not determine changes in immunity in individual children. Therefore, long-term follow-up studies are necessary to understand the dynamics of VZV immunity. Nevertheless, to our knowledge, this study is the first report to evaluate the varicella immune status of healthy children aged 1-6 years in Korea and to represent the antibody titer of varicella vaccines as an international unit.

\section{Conclusions}

A one-dose regimen of varicella vaccine reduced the overall incidence of varicella in healthy Korean children compared to unvaccinated children. However, similar to waning of natural immunity, vaccine-induced immunity seemed to be waning especially after 4 years old. Thus, some of the healthy children are still vulnerable to varicella. Many countries adopt a two-dose regimen for varicella vaccine. This is more effective than a one-dose regimen to protect breakthrough infection and outbreaks. Therefore, a two-dose regimen would be reasonable to protect children from varicella disease.

Author Contributions: Conceptualization, H.P.; Methodology, Y.K.; Validation, Y.K., J.-Y.H. and K.-M.L.; formal analysis, Y.K.; investigation, Y.K., J.-Y.H. and K.-M.L.; resources, E.L., Y.K., J.-Y.H. and K.-M.L.; writing-original draft preparation, Y.K.; writing-review and editing, H.P.; project administration, H.P.; funding acquisition, H.P. All authors have read and agreed to the published version of the manuscript.

Funding: This research was funded by the Ministry of Food and Drug Safety in 2009 and 2013, grant numbers 09122KFDA423 and 13172KFDA315.

Institutional Review Board Statement: The study was conducted in accordance with the guidelines of the Declaration of Helsinki and approved by the Institutional Review Board of Yeungnam Uni- 
versity Medical Centers (protocol code PCR-09-23, date of approval at 25 May 2010, protocol code YUH-13-0330-O16 and date of approval at 4 April 2013).

Informed Consent Statement: Written informed consent was obtained from the parents of all subjects involved in this study.

Data Availability Statement: The data presented in this study are available on request from the corresponding author.

Conflicts of Interest: The authors declare no conflict of interest.

\section{References}

1. Hope-Simpson, R.E. The Nature of Herpes Zoster: A Long-Term Study and a New Hypothesis. Proc. R. Soc. Med. 1965, 58, 9-20. [CrossRef]

2. Galil, K.; Brown, C.; Lin, F.; Seward, J. Hospitalizations for varicella in the United States, 1988 to 1999. Pediatr. Infect. Dis. J. 2002, 21, 931-935. [CrossRef] [PubMed]

3. Meyer, P.A.; Seward, J.F.; Jumaan, A.O.; Wharton, M. Varicella mortality: Trends before vaccine licensure in the United States, 1970-1994. J. Infect. Dis. 2000, 182, 383-390. [CrossRef] [PubMed]

4. Lee, H. Survey on Efficacy and Safety of Varicella Vaccine as a Regular Vaccine in Korea. 2005, Volume 139. Available online: https:/ / scienceon.kisti.re.kr/srch/selectPORSrchReport.do?cn=TRKO201300000675 (accessed on 5 April 2021).

5. Kim, K.Y.; Jeon, S.Y.; Jeon, M.J.; Lee, K.H.; Lee, S.G.; Kim, D.; Kang, E.; Bae, S.G.; Kim, J. Health impact assessment of free immunization program in Jinju City, Korea. J. Prev. Med. Public Health 2012, 45, 267-275. [CrossRef] [PubMed]

6. Lee, H.K.; Kim, S.H.; Chun, B.C.; Kim, K.H.; Lee, H.J. Vaccination coverage in Korean children of six years old and younger. In Proceedings of the 57th Annual Fall Meeting of the Korean Pediatric Society, Seoul, Korea, 19-20 October 2007; p. 90.

7. Park, B.; Lee, Y.K.; Cho, L.Y.; Go, U.Y.; Yang, J.J.; Ma, S.H.; Choi, B.Y.; Lee, M.S.; Lee, J.S.; Choi, E.H.; et al. Estimation of nationwide vaccination coverage and comparison of interview and telephone survey methodology for estimating vaccination status. J. Korean Med. Sci. 2011, 26, 711-719. [CrossRef] [PubMed]

8. Statistics for Inoculation Rate in Varicella Vaccine. Korean Statistical Information Service. Available online: https://kosis.kr/ statHtml/statHtml.do?orgId=177\&tblId=DT_11793N_171\&conn_path=I3 (accessed on 6 April 2021).

9. Infectious Disease Surveillance Annual Report 2005-2019. Korea Disease Control and Prevention Agency, Infectious Disease Portal. Available online: http:/ / www.kdca.go.kr/npt/biz/npp/ist/bass/bassSexdstnAgeStatsMain.do\# (accessed on 6 April 2021).

10. Kang, J.H.; Kim, J.H.; Hur, J.K.; Woo, K. Tow-Year Follow-up Study for Clinical Feature and Immunity of The Children, Vaccinated by 47 Passaged Oka Strain Live Attenuated Varicella Vaccine. Korean J. Pediatr. Infect. Dis. 2000, 7, 129-135. [CrossRef]

11. Kim, Y.H.; Hwang, J.Y.; Shim, H.M.; Lee, E.; Park, S.; Park, H. Evaluation of a commercial glycoprotein enzyme-linked immunosorbent assay for measuring vaccine immunity to varicella. Yonsei Med. J. 2014, 55, 459-466. [CrossRef] [PubMed]

12. Williams, V.; Gershon, A.; Brunell, P.A. Serologic response to varicella-zoster membrane antigens measured by direct immunofluorescence. J. Infect. Dis. 1974, 130, 669-672. [CrossRef]

13. Arnedo-Pena, A.; Puig-Barbera, J.; Aznar-Orenga, M.A.; Ballester-Albiol, M.; Pardo-Serrano, F.; Bellido-Blasco, J.B.; Romeu-Garcia, M.A. Varicella vaccine effectiveness during an outbreak in a partially vaccinated population in Spain. Pediatr. Infect. Dis. J. 2006, 25, 774-778. [CrossRef]

14. Gershon, A.A.; Krugman, S. Seroepidemiologic survey of varicella: Value of specific fluorescent antibody test. Pediatrics 1975, 56, 1005-1008. [PubMed]

15. Kurugol, Z.; Halicioglu, O.; Koc, F.; Koturoglu, G.; Aksit, S. Varicella rates among unvaccinated and one-dose vaccinated healthy children in Izmir, Turkey. Int. J. Infect. Dis. 2011, 15, e475-e480. [CrossRef] [PubMed]

16. Spackova, M.; Wiese-Posselt, M.; Dehnert, M.; Matysiak-Klose, D.; Heininger, U.; Siedler, A. Comparative varicella vaccine effectiveness during outbreaks in day-care centres. Vaccine 2010, 28, 686-691. [CrossRef] [PubMed]

17. Tafuri, S.; Martinelli, D.; De Palma, M.; Germinario, C.; Prato, R. Report of varicella outbreak in a low vaccination coverage group of otherwise healthy children in Italy: The role of breakthrough and the need of a second dose of vaccine. Vaccine 2010, 28, 1594-1597. [CrossRef]

18. Tafuri, S.; Martinelli, D.; Prato, R.; Germinario, C. Vaccine effectiveness evaluation during a varicella outbreak among children of primary schools and day-care centers in a region which adopted UMV. Hum. Vaccines Immunother. 2013, 9, 184-188. [CrossRef] [PubMed]

19. Vazquez, M.; LaRussa, P.S.; Gershon, A.A.; Steinberg, S.P.; Freudigman, K.; Shapiro, E.D. The effectiveness of the varicella vaccine in clinical practice. N. Engl. J. Med. 2001, 344, 955-960. [CrossRef]

20. Michalik, D.E.; Steinberg, S.P.; Larussa, P.S.; Edwards, K.M.; Wright, P.F.; Arvin, A.M.; Gans, H.A.; Gershon, A.A. Primary vaccine failure after 1 dose of varicella vaccine in healthy children. J. Infect. Dis. 2008, 197, 944-949. [CrossRef] [PubMed]

21. Plotkin, S.A.; Orenstein, W.A.; Offit, P.A. Vaccines, 6th ed.; Elsevier Saunders: Philadelphia, PA, USA, 2013.

22. Oh, S.H.; Choi, E.H.; Shin, S.H.; Kim, Y.K.; Chang, J.K.; Choi, K.M.; Hur, J.K.; Kim, K.H.; Kim, J.Y.; Chung, E.H.; et al. Varicella and varicella vaccination in South Korea. Clin. Vaccine Immunol. 2014, 21, 762-768. [CrossRef]

23. Lee, H.; Cho, H.K.; Kim, K.H. Seroepidemiology of varicella-zoster virus in Korea. J. Korean Med. Sci. 2013, 28, 195-199. [CrossRef] 
24. Choi, U.Y.; Huh, D.H.; Kim, J.H.; Kang, J.H. Seropositivity of Varicella zoster virus in vaccinated Korean children and MAV vaccine group. Hum. Vaccines Immunother. 2016, 12, 2560-2564. [CrossRef]

25. Ndumbe, P.M.; Cradock-Watson, J.; Levinsky, R.J. Natural and artificial immunity to varicella zoster virus. J. Med. Virol. 1988, 25, 171-178. [CrossRef]

26. Jeon, J.S.; Won, Y.H.; Kim, I.K.; Ahn, J.H.; Shin, O.S.; Kim, J.H.; Lee, C.H. Analysis of single nucleotide polymorphism among Varicella-Zoster Virus and identification of vaccine-specific sites. Virology 2016, 496, 277-286. [CrossRef]

27. MMWR Recommendations and Reports; Centers for Disease Control and Prevention: Atlanta, GA, USA, 2006; pp. 1-48. Available online: https: / / www.cdc.gov/mmwr/preview/mmwrhtml/rr5515a1.htm (accessed on 6 April 2021).

28. Garcia Cenoz, M.; Castilla, J.; Chamorro, J.; Martinez-Baz, I.; Martinez-Artola, V.; Irisarri, F.; Arriazu, M.; Ezpeleta, C.; Barricarte, A. Impact of universal two-dose vaccination on varicella epidemiology in Navarre, Spain, 2006 to 2012. Eurosurveillance 2013, 18, 20552. [CrossRef] [PubMed]

29. Ozaki, T. Varicella vaccination in Japan: Necessity of implementing a routine vaccination program. J. Infect. Chemother. 2013, 19, 188-195. [CrossRef]

30. Pozza, F.; Piovesan, C.; Russo, F.; Bella, A.; Pezzotti, P.; Emberti Gialloreti, L. Impact of universal vaccination on the epidemiology of varicella in Veneto, Italy. Vaccine 2011, 29, 9480-9487. [CrossRef] [PubMed]

31. Siedler, A.; Arndt, U. Impact of the routine varicella vaccination programme on varicella epidemiology in Germany. Eurosurveillance 2010, 15, 19530. [CrossRef]

32. NCIRS Fact Sheet: Varicella-Zoster (Chickenpox) Vaccines For Australian Children: Information For Immunisation Providers 2015. Available online: https://www.ncirs.org.au/sites/default/files/2018-12/varicella-fact-sheet.pdf (accessed on 6 April 2021).

33. Jung, J.; Ko, Y.J.; Kim, Y.E.; Huh, K.; Park, B.J.; Yoon, S.J. Epidemiological Impact of the Korean National Immunization Program on Varicella Incidence. J. Korean Med. Sci. 2019, 34, e53. [CrossRef]

34. Lee, Y.H.; Choe, Y.J.; Cho, S.I.; Kang, C.R.; Bang, J.H.; Oh, M.D.; Lee, J.K. Effectiveness of Varicella Vaccination Program in Preventing Laboratory-Confirmed Cases in Children in Seoul, Korea. J. Korean Med. Sci. 2016, 31, 1897-1901. [CrossRef]

35. Shapiro, E.D.; Vazquez, M.; Esposito, D.; Holabird, N.; Steinberg, S.P.; Dziura, J.; LaRussa, P.S.; Gershon, A.A. Effectiveness of 2 doses of varicella vaccine in children. J. Infect. Dis. 2011, 203, 312-315. [CrossRef]

36. Chan, Y.D.; Edmunds, W.J.; Chan, H.L.; Wong, M.L.; Au, K.A.; Chuang, S.K.; van Hoek, A.J.; Flasche, S. Varicella vaccine dose depended effectiveness and waning among preschool children in Hong Kong. Hum. Vaccines Immunother. 2020, 16, 499-505. [CrossRef] [PubMed] 